\title{
BRASH syndrome associated with angiotensin receptor blocker and SGLT2 inhibitor
}

\author{
Takahiko Nagamine ${ }^{1,2}$ (])
}

Received: 10 August 2021 / Accepted: 23 August 2021 / Published online: 1 October 2021

(c) The Author(s), under exclusive licence to Canadian Association of Emergency Physicians (CAEP)/ Association Canadienne de Médecine d'Urgence (ACMU) 2021

Keywords BRASH syndrome - SGLT2 inhibitor - Angiotensin receptor blocker

Dear Editor,

BRASH syndrome is a relatively new entity, defined as a combination of bradycardia, renal failure, atrioventricular nodal blockade, shock, and hyperkalemia [1]. According to the Advanced Cardiac Life Support (ACLS) algorithm, if there are signs of shock due to bradycardia, atropine should be administered, and if atropine does not work, percutaneous pacing should be considered [2]. However, bradycardia due to BRASH syndrome does not respond to this algorithm [3].

An 83-year-old woman was brought to the emergency room complaining of severe general malaise that progressed to syncope. She had type 2 diabetes and hypertension for 20 years. She is currently taking azilsartan $20 \mathrm{mg} /$ day, bisoprolol $5 \mathrm{mg} /$ day, ipragliflozin $50 \mathrm{mg} /$ day, and metformin $500 \mathrm{mg} /$ day. On arrival, her vital signs showed a blood pressure of $68 / 44 \mathrm{mmHg}$, a temperature of $36.8^{\circ} \mathrm{C}$, a respiratory rate of 22 breaths/minute, and an oxygen saturation of $99 \%$ on $3 \mathrm{~L} / \mathrm{min}$ of nasal cannula oxygen. Blood work showed blood glucose $363 \mathrm{mg} / \mathrm{dL}$, sodium $123 \mathrm{mEq} / \mathrm{L}$, potassium $7.8 \mathrm{mEq} / \mathrm{L}$, urea nitrogen $76.9 \mathrm{mg} / \mathrm{dL}$, creatinine $3.26 \mathrm{mg} /$ $\mathrm{dL}$, and $\mathrm{HbA} 1 \mathrm{c} 10.2 \%$. The ECG monitor showed a marked bradycardia with a wide QRS and a peaked $\mathrm{T}$ wave. We performed a 12-lead ECG, which showed significant bradycardia of 24 beats per minute with atrioventricular nodal blockade. A diagnosis of BRASH syndrome was made based on the presence of symptomatic bradycardia with ECG findings, baseline renal dysfunction, hyperkalemia,

Takahiko Nagamine

tnagamine@outlook.com

1 Sunlight Brain Research Center, 4-13-18 Jiyugaoka, Hofu, Yamaguchi 747-0066, Japan

2 Department of Emergency Medicine, Matsumoto Surgical Hospital, Hofu, Yamaguchi, Japan and long-term ingestion of beta-blocker. We started massive saline infusion with rapid-acting insulin $0.1 \mathrm{U} / \mathrm{kg} / \mathrm{hour}$, and $10 \mathrm{~mL}$ of $8.5 \%$ calcium gluconate hydrate was infused. As the serum potassium level decreased with insulin drip infusion, her bradycardia improved. The next day, her blood tests revealed blood glucose $189 \mathrm{mg} / \mathrm{dL}$, sodium $136 \mathrm{mEq} / \mathrm{L}$, potassium $5.6 \mathrm{mEq} / \mathrm{L}$, urea nitrogen $42.2 \mathrm{mg} / \mathrm{dL}$, creatinine $2.13 \mathrm{mg} / \mathrm{dL}$. The ECG at this time showed a heart rate of 57 beats per minute, and a peaked $\mathrm{T}$ wave disappeared.

Treatment of BRASH syndrome is aimed at rapid management of hyperkalemia, with intravenous calcium to stabilize the cardiac membrane [4]. Hyperkalemia in this case was triggered by angiotensin receptor blocker (ARB) and sodium-glucose cotransporter 2 (SGLT2) inhibitor. ARBs inhibit renal excretion of potassium. SGLT2 inhibitors have osmotic diuretic and natriuretic effects [5]. Therefore, in this case, dehydration caused by SGLT2 inhibitor led to decline in renal function, which, combined with delayed potassium excretion by ARB, led to rapid progression of hyperkalemia. The lesson from this case is that BRASH syndrome can occur with commonly used drugs to treat hypertension and diabetes, such as ARBs and SGLT2 inhibitors.

\section{Declarations}

Conflict of interest The author declares no conflict of interest.

\section{References}

1. Farkas JD, Long B, Koyfman A, Menson K. BRASH syndrome: bradycardia, renal failure, AV blockade, shock, and hyperkalemia. J Emerg Med. 2020;59(2):216-23.

2. Hemmer N, Venkat A. Hyperkalemia and atrial pacemakers: what can the electrocardiogram tell you? CJEM. 2011;13(6):409-10. 
3. Sattar Y, Bareeqa SB, Rauf H, Ullah W, Alraies MC. Bradycardia, renal failure, atrioventricular-nodal blocker, shock, and hyperkalemia syndrome diagnosis and literature review. Cureus. 2020;12(2):e6985.

4. Schnaubelt S, Roeggla M, Spiel AO, Schukro C, Domanovits $\mathrm{H}$. The BRASH syndrome: an interaction of bradycardia, renal failure, AV block, shock and hyperkalemia. Intern Emerg Med. 2021;16(2):509-11.
5. Donnan JR, Grandy CA, Chibrikov E, Marra CA, Aubrey-Bassler K, Johnston K, Swab M, Hache J, Curnew D, Nguyen H, Gamble JM. Comparative safety of the sodium glucose co-transporter 2 (SGLT2) inhibitors: a systematic review and meta-analysis. BMJ Open. 2019;9(1):e022577. 